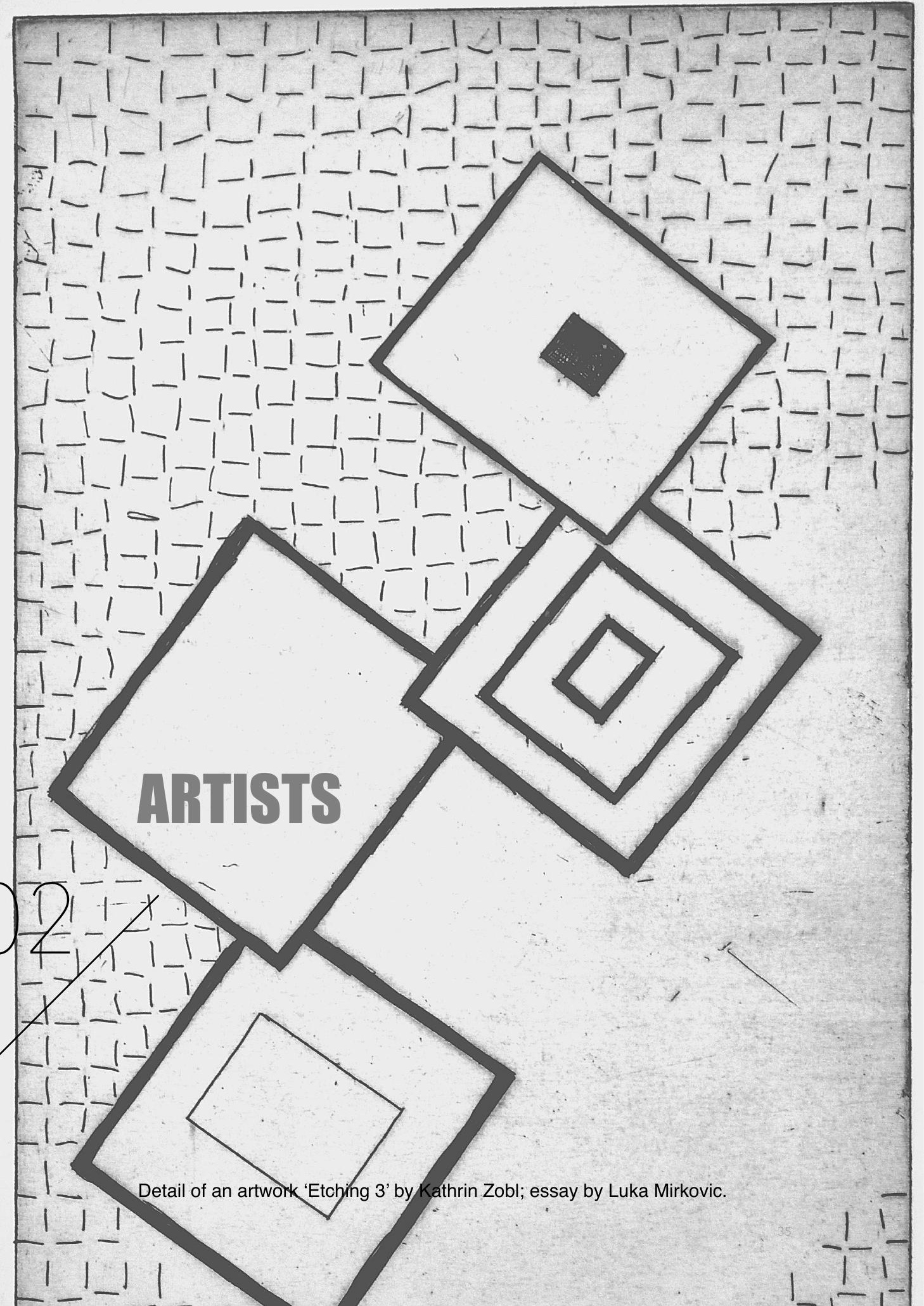




\title{
Hegemonies in Art: Struggles of an Aspiring Artist
}

\author{
Luka Mirković
}

Seeing as visual art, such as Etching 3 manifests itself physically, as an object, which, if a young artist is to live off of, must be sold, the process of commoditization demands being taken apart. Commoditization entails the placement of value on an object, in the broadest sense of the manner - a monetary value or an equitability to others (Kopytoff 1988, 64 \& 68-69). Essentially an object is turned into a commodity. The lack of a monetary system does not inhibit this phenomenon in the slightest, with many indigenous societies having maintained their own exchange systems, amongst themselves and other such societies. It was an ethnography on the Kula - a complex exchange system amongst indigenous peoples of the Trobriand Islands, which first put to use, and helped draft up the method of participant observation, central to modern ethnographic fieldwork (see Malinowski 1922 [1932], 1-25). As Kopytoff has extensively explored in his piece on commoditization, there are distinctions to be made between commoditization in such societies and modern societies. We must recognize that culture has the defining role in managing commoditization, and its opposite, singularization the deeming of an object as priceless, which can be seen across complex and simple societies: in the unsaleability of cultural artefacts, the declaration of objects as national treasures, and the enforcement of taboos, or the prohibition of trade in certain objects (Kopytoff 1988, 71-73). These two processes are by no means separate and often intertwined. These two types of society are most distinguishable from one another in their understanding and acceptance of value universals. Simple societies, even without currency, have been shown to have value spheres, namely, groupings of objects deemed tradeable with others within the group, which, along with the singularization of separate selected objects are generally taken for granted by the population. Discrepancies between individual and societal value of objects are far more common in western societies precisely due to the lack of such universal understanding. The personal value of objects to individuals, if they are to be assigned a value - that is, commoditized, can be very different to their monetary value on a societal level, which can be at the mercy of market forces of supply and demand, as well as prices determined by elite circles enforcing hegemony. Value spheres, as seen in indigenous societies, are virtually nonexistent and by no means universally accepted (see again Kopytoff 1988 for a side by side comparison of these phenomena across both types of society). The movement of objects and their change in value, in the broadest sense of the term, requires an understanding which recognizes the dynamic character of such associations - this is found in Appadurai's key text, 'Regimes of Value'. This theory is such that as objects circulate amongst differing institutions, individuals or societies/cultures, their interpretation by any of these will also change, these are very fluid or dynamic (for an extension of this theory, exemplifying the dynamic character of value as objects circulate amongst institutions see Myers 2001). Art undergoes various stages of redefining of its value, and its apparent status as it circulates amongst individuals and institutions. In contemporary western society, artists are the embodiment of the lack of coordination of value/ regimes of value, or singularization and commoditization. Art, seen as a higher characteristic of human productivity, is usually thought of as made of singular objects, 
as something above mere consumerism, yet the very existence of the niche art market counters this. This goes so far as the redefinition of permanent collections in contemporary museums as assets. If we follow Thorton, for whom, as she points out in her book Seven Days in the Artworld - art dealers occupy the most pivotal role of the 6 stereotypes that make up the art world (artist, dealer, critic, curator, collector, auctionhouse expert), artist's works are doomed to be commoditized in line with this closed group and its hegemonies (Thorton 2012, xi-xx). The prized work of an artist, having a personal, singular value, will be commoditized by the art market and its members, if it is to be sold. This represents the commoditization of a singularized object, and the transcendence through regimes of value, as it is evaluated by the art dealer and the market/ sphere he represents. The artist is powerless in respect to the opinions of this closed group and its members and may feel cheated by this commoditization process, while so much of their success and livelihood depends on the very same. Kathrin Zobl, represented in our exhibition, voiced her frustrations about her course at university that systematically catered to such hegemonies, and she was abashed upon hearing, from her personal tutor, that an artist's role within society, is first and foremost to produce the art that society demands and that can be sold! Aspiring artists in western society must face the fact that, unlike in indigenous ones, there are no universal spheres and equations of value on which they can rely, which as illustrated in the case just mentioned, may seep into their education and, if they choose to buckle to such pressure, into their personal style; hence, their freedom to create will be severely limited.

An interesting protest to the processes of commoditization and commercialization can be found, paradoxically, in the re-interpretation of many characteristics associated with capitalism itself, and the free market. This counter movement, embodied in the early minimalism of the 1960s, not only plays on these aspects of capitalism, but the very notion that artworks should be inherently unique, priceless, or, to remain in tune with the concepts in this text, singularized. As argued by Krauss, early minimalist works - as opposed to the use of fine materials resulting in unique pieces - were created in what can be described as an industrial manner (Krauss 1990, 3-17). Not only were industrial materials (plexiglass, plastics, metal) incorporated into such works, but the very method of their production was industrial. As opposed to being fabricated individually, by the artist, such works were usually created through the use of print or sculpted from a mould. These characteristics mean that, in theory, the resulting works are not unique, and possession of the press/print gives the owner the power to create as many of these as they see fit. The singularity that is characteristic of art, the paradox of a unique object above commodification, yet whose pricelessness is determined by precisely this, is taken apart by challenging this very singularity. The ability to produce countless copies is much like production in a factory, of objects deemed for mass consumption, which, in western understanding of material culture are almost always commoditized. Many members of this movement acted precisely on these possibilities, and challenged stereotypes of the art world of the time, by using the opportunities these new production methods allowed, producing multiple copies of works. Such is the case for Etching 3, which is essentially a small metal press, with the engravings carved in by Kathrin. This piece shows that methods of classic minimalism can be appropriated even by a young art student. These revolutionary processes can, and have been taken even further, through the actual selling of rights of press/frame, or blueprints to create another one, to third parties (see Krauss 1990). This means that the artist's ability to actually create 
their works, and even create multiple copies and control their amount on the market, is transferred to another individual. The very characteristics of consumerism and capitalism, and of industrial processes can be not only used to re-interpret how we think of art, but also as an act of ingenious protest against these, and elitisms carried by them.

A further means to escape the consumerist mould, which undoubtedly has had its effect on the art world, can possibly be found in breaking down some of the complexities taken for granted in contemporary western society, taking an example from the less complex, indigenous societies, and pre-monetary trading systems. Seeing as the art world, regardless of its overlaps with capitalism, and internal elitisms, has throughout its history been often associated with rebellion - populated by the bohemian - alternatives may be found within this society. Undiscovered talents, in particular, aspiring artists, and art students face financial struggles and are often linked with other creative circles alternative political movements, communes, members of other art disciplines, independent artists, all of whom face similar challenges. In conversing with Kathrin, I learned that since leaving school, she would often exchange a painting, a piece of hers, for a favour from a friend. Imagining this on a larger scale, say, in the closed society just described, it could be possible to incorporate some form of independent trade of artworks for objects/favours insofar as financial insecurity is felt by both parties. If carried on long enough, independent value spheres, much like those of non-monetary societies may take form and become universally accepted by those who use them, resulting in less disappointment/ uncertainty for aspiring artists when commodifying their works. While the formation of larger, universal value spheres may seem far-fetched as of now, one cannot help but play with the idea, seeing as, as mentioned above, some of the principles (object - object/favour trade) for such a structure, do in fact occur within the western society.

Another integral process involving art, other than those linked to its selling, is undoubtedly its consumption. At the end of the day, it only seems logical that this is what art is for. Much like within minimalist discourse, the solutions or alternatives to problems felt, and their sources prove to be more connected than one would expect, and cannot be so easily separated. How a piece is viewed, the experience of viewing it, where this should be done, and who determines all this are relevant questions. Museums must be understood as more than mere spatial locations housing exhibitions, these are social institutions, within which a variety of social activity takes place (see Handler 1993, 33-36). If going by Gell, social actors can transfer agency into objects, essentially turning these into 'secondary agents', the actors being 'primary agents'. This means, that if he is a 'patient', the agency transferred into, say, artwork, by its creator, can be felt by a viewer, a process known as 'distributed personhood' (Gell 1998, 7-26). The display, namely, consumption of a painting, and all possible third party elements can affect how this occurs: the emotions felt when viewing the artwork, the transfer, if there is any, of the artist's message onto the viewer; a fundamental change in the viewer's worldview, debate surrounding the piece, changes made to theory in any discipline in academia. There exists, therefore an extensive theory on museum display methods, covering a range of subject areas. Having a piece shown in such an institutional setting, can vastly enhance the overall experience of viewing it: how it is juxtaposed with other works, or segregated from them, similarly the literature accompanying it, or lack thereof, the lighting of the room containing a piece; even how a patient is navigated toward a piece, 
insofar as this is done, the obstacles he must navigate through to reach it are all of relevance here (See Moser 2010, 22-32 \& Herle 2013 113-135). Duncan compares visits to the museum to religious ritual, a form of performance of rites, in which both artworks and viewers are involved, which can result in a revelation - much like religious enlightenment, the museum experience being the religion of the enlightenment (Duncan 2005). Museums do, however, come with limitations. These include not only the physical limitations linked to the museum as a space but also structural hierarchies contained within, amongst the staff, as well as, seeing as the contemporary museum is increasingly put under pressure from free-market capitalism, financial pressures and its limitations. There can be misalignment amongst staff members, with curators, project managers, and in house academics working against each other, even separated into different departments (see Terell 1993, 149-53, for how financial pressure can segment museum staff). Whether the artist is even given the freedom to have their work displayed as they see fit is naturally also of relevance, structural misalignment only serves to obscure this further. What is clear is that regardless of the many limitations that come with displaying art in a museum, choosing such institutions to house art can significantly enhance the viewing/appreciation of a piece, and thus aid processes such as 'distributed personhood', resulting in the appreciation of the artist, and their motives.

An alternative, in many ways even more daring than the challenges to conventions and the desire for uniqueness perpetrated by the minimalists of the 1960s, would be to skip the institution entirely. While laughable upon first hearing, this occurs all around us. We, who live in urban settings are surrounded by it: street art. This term includes art done in, or perhaps more precisely on the public sphere. In this case, the artwork is placed/ painted/sprayed straight into place, mostly illegally, onto public/ private property (Schackter 2008, 35-61). There is no limit to who can view these pieces, no guidelines as to how one should view them; the only limitations that are taken for granted are the actual physical properties of the streets and cities containing them. The risks can be great, not only in terms of legality, but also to the artworks themselves, as unlike when privately owned and protected, nothing bars natural decay through erosion, or vandalism and painting over by other artists. While allowing for a large audience, this form of display challenges the very capitalist concept of private property and can bring the viewer to question the alternative offered by this system: advertising, which can just as well be interpreted as a breach of the public space (Schackter 2008). One may claim that such an approach is fruitless to the aspiring artist, as they will not be paid for such work, but interestingly enough, many members of this movement have managed to gain a reputation through this vigilante method, becoming respected artists who sell their work - just think of Banksy.

In current times, the aspiring artist is faced with mounting pressures from varying institutions, which can find their way into the artists' education, and thus, their art. This pressure mostly manifests itself in a breach of their autonomy, subjecting them to hierarchies and hegemonies. When taking into regard the value, valuing and viewing of their art, aspiring artists must face a variety of decisions, and possibly make sacrifices to their autonomy, from the side of the institutions - the art market, places of education and the museum/gallery. In regards to the museum, the matter can become even more confusing, as placing art in such institutions can enhance the appreciation of a piece if the conditions are favourable, just as much as take this process out of the artist's hand, 
diverting the agency they confer upon it. It is no wonder that artists have, and currently are finding alternatives to the models that have become conventional in a consumerist western society, as is Kathrin's case. Reaching into the actual root of such conventions, as was done by minimalists, can prove an effective alternative, which acts as a protest, just as well as taking inspiration from alternative trading systems, borrowing from the so called 'primitive' societies. All this can be said for street art, which, if looking back, reminds of the earliest forms of art, seeing as cave paintings, by today's standards, would mostly be considered graffiti. Who knows, maybe it will become a common practice in the future, for an aspiring artist to spray paint a shop with a stencil, in exchange for groceries for the week, only to trade the stencil itself for all the necessary materials to make another.

Duncan, Garol. 2005. Civilizing rituals: Inside public art museums. London: Routledge.

Gell, Alfred. 1998. Art and Agency. Oxford: Oxford University Press.

Handler, Richard. 1990. 'An anthropological definition of the museum and its purpose.' Museum Anthropology 17(1): 33-36.

Herle, Anita. 2013. 'Exhibitions as Research: Displaying the Technologies That Make Bodies Visible.' In Museum Worlds 17(1): 113-135.

Kopytoff, Igor. 1988. 'The cultural Biography of Things: commoditization as a process.' In The social life of things: Commodities in cultural perspective Ed. Appadurai, Arjun, Cambridge University Press, pp. 65-91.

Malinowski, Bronislaw. 1922 [1932] Argonauts of the western Pacific, London: Routledge.

Myers, Fred. 2001. Empire of Things: Regiemes of Value and Material Culture, Santa Fe: School of American Research Press.

Thornton, Sarah. 2012. Seven Days in the Art World. London: Granta Books.

Schackter, Rafael. 2008. 'An Ethnography of Iconclash: An Investigation into the Production, Consumption and Destruction of Street- Art in London,' Fournal of Material Culture, 13(1): 35-61.

Krauss, Rosalind. 1990. 'The Cultural Logic of the Late Capitalist Museum.' October 54: 3-17. doi:10.2307/778666.

Terrell, John. 1991. 'Disneyland and the Future of Museum Anthropology.' American Anthropologist, New Series, 93(1): 149-53. 